\title{
PELATIHAN PEMANFAATAN TEKNOLOGI KOMPUTER DALAM PENGOLAHAN DATA PASIEN PADA UPT. PUSKESMAS PORSEA
}

\author{
Risnawati*1 $^{1}$, Masitah Handayani ${ }^{2}$, Syartika Anggraini ${ }^{3}$ \\ ${ }^{1}$ Sistem Komputer, ${ }^{2,3}$ Sistem Informasi, STMIK Royal Kisaran \\ Jl. Prof H. M. Yamin, SH, No 173, Kisaran, Kabupaten Asahan, Sumatera Utara \\ email:* rhisnawati716@gmail.com
}

\begin{abstract}
Community Service activities are in the form of training in the use of computer technology for health workers, especially the patient registration section in the UPT Porsea Health Center environment, aimed at providing knowledge and skills, which are expected to produce changes in knowledge and skills from teachers and students so that the learning and teaching process can run smoothly and easily. The target audience in this Community Service activity is all health workers on duty in the patient registration section. Training activities on the use of computer technology in the world of health are presented with lecture methods, demonstrations and question and answer. Benefits obtained from this activity include increasing knowledge of staff health to be more professional in processing the data of patients who are treated at the UPT Porsea Health Center in order to manage patient data effectively and efficiently in science and technology mastery, so that it can simplify the process of calculating the number of patients treated computerically with the help of Microsoft Excel.
\end{abstract}

Keywords: Utilization of Computer Technology, Microsoft Excel, Patient Data Processing

\begin{abstract}
Abstrak: Kegiatan Pengabdian kepada Masyarakat berupa pelatihan pemanfaatan teknologi komputer bagi tenaga kesehatan khususnya bagian pendaftaran pasien di lingkungan UPT Puskesmas Porsea ini bertujuan untuk memberikan pengetahuan dan keterampilan, yang diharapkan dapat menghasilkan perubahan pengetahuan, keterampilan dan sikap dari guru maupun siswa sehingga proses belajar dan mengajar dapat berjalan dengan lancar dan mudah.Khalayak sasaran dalam kegiatan Pengabdian kepada Masyarakat ini adalah seluruh tenaga kesehatan yang bertugas di bagian pendaftaran pasien. Kegiatan pelatihan pemanfaatan teknologi komputer dalam dunia kesehatan ini disajikan dengan metode ceramah, demonstrasi dan tanya jawab. Manfaat yang diperoleh dari kegiatan ini antara lain dapat meningkatkan pengetahuan tenaga kesehatan agar lebih profesional dalam mengolah data pasien yang berobat di UPT Puskesmas Porsea agar dapat mengelola data pasien secara efektif dan efisien dalam penguasan IPTEKS, sehingga dapat mempermudah proses perhitungan jumlah pasien yang berobat secara komputerisasi dengan bantuan Microsoft Excel.
\end{abstract}

Kata Kunci : Pemanfaatan Teknologi Komputer, Microsoft Excel, Pengolahan Data Pasien 
Available online at https://jurnal.stmikroyal.ac.id/index.php/jurdimas

\section{PENDAHULUAN}

Kemajuan teknologi komputer sebagai pendukung pemrosesan data dan informasi telah menjadi kebutuhan pokok dalam suatu instansi. Instansi jasa pelayanan yang memberikan pelayanan kepada masyarakat, sangat membutuhkan kecepatan pelayanan informasi sehingga dapat memberikan pelayanan yang optimal kepada pelanggannya.

Puskesmas sebagai jasa pelayanan kesehatan, membutuhkan komputer sebagai alat pemrosesan dan penyajian informasi. Puskesmas yang kesehariannya memberikan pelayanan kesnehatan kepada masyarakat, merupakan sektor instansi kesehatan yang berkembang dengan cepat seiring bertambahnya penduduk. Kualitas pelayanan kepada pasien merupakan hal pokok yang senantiasa menjadi titik sentral setiap Puskesmas, oleh sebab itu manajemen Puskesmas membutuhkan suatu sistem informasi yang mampu memberikan informasi yang cepat kepada pasien dan masyarakat.

Sebagai instansi pemerintah dalam memberikan jasa pelayanan kesehatan di Porsea, UPT. Puskesmas Porsea melayani transaksi pasien dalam kesehariannya. Dan terdapat beberapa masalah di sana, antara lain pengolahan data pasien masih menggunakan cara manual, dimana proses tersebut memerlukan proses dan waktu yang cukup lama dalam proses pengolahan datanya sehingga mengakibatkan penggunaan waktu yang tidak efisien dan keterlambatan pelayanan. Selain itu juga terdapat masalah pada pengarsipan serta pembuatan laporan yang kurang efektif yang mengakibatkan terjadinya pengulangan pada data yang sama sehingga laporan sering terlambat dan hasilnya kurang akurat.

Oleh sebab itu, pemanfaatan teknologi komputer sangat membantu dalam proses pengolahan data di Puskesmas, khususnya dalam pengolahan data pasien.

Adapun rumusan masalah dalam kegiatan ini adalah:

1. Bagaimana memberikan pelatihan tenaga kesehatan dalam mengelola data pasien menggunakan perangkat lunak MS. Excell?

2. Apa kendala-kendala yang dihadapi oleh tenaga medis dalam menggunakan perangkat lunak MS. Excell pada proses pengolahan data pasien?

Kegiatan Pengabdian kepada Masyarakat Pelatihan Pemanfaatan Teknologi Komputer Dalam Pengolahan Data Pasien ini bertujuan untuk memberikan pengetahuan dan keterampilan, yang diharapkan dapat menghasilkan perubahan pengetahuan, keterampilan tenaga medis yang bertugas di bagian pendaftaran dalam mengolah data pasien yang berobat dengan mudah, cepat dan tepat. Selain itu, kegiatan ini mengajarkan kepada tenaga medis bagaimana mengolah data dengan mudah menggunakan komputerisasi.

Manfaat yang diperoleh dari pelaksanaan pengabdian kepada masyarakat ini adalah, bagi para pengabdi khususnya dapat menjadi wahana latihan mengembangkan kemampuan komunikasi kemasyarakatan, mengembangkan pengetahuan dan wawasan tentang perangkat lunak Microsoft Excel, melatih dan mengembangkan kemampuan manajemen baik waktu maupun masa. Sedangkan secara institusional pengabdian masyarakat ini bermanfaat untuk melakukan sosialisasi institusi kepada masyarakat.

Pengabdian kepada Masyarakat ini yang menjadi peserta adalah tenaga medis pada UPT. Puskesmas Porsea yang bertugas pada bagian pendaftaran pasien.

Rangkaian kegiatan pengabdian masyarakat dilaksanakan selama 2 hari dan dapat diuraikan pada tabel berikut ini:

\section{METODE}

Metode pelaksanaan dalam pengabdian masyarakat ini adalah bentuk 
Available online at https://jurnal.stmikroyal.ac.id/index.php/jurdimas

pelatihan di dalam ruangan dengan metode ceramah, diskusi dan tanya jawab serta praktek pembukuan secara langsung.

Berikut beberapa foto kegiatan pengabdian kepada masyarakt di puskesmas Porsea :

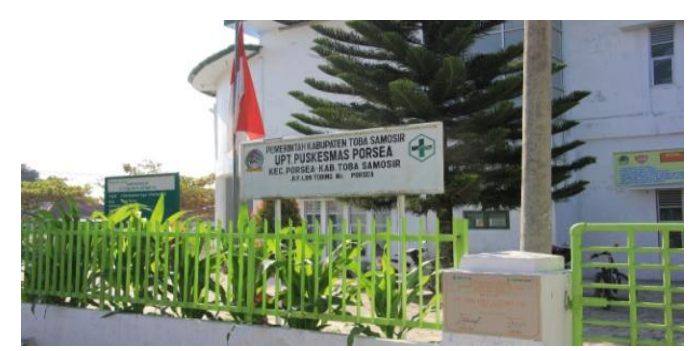

Gambar 1. Gebang Puskesmas

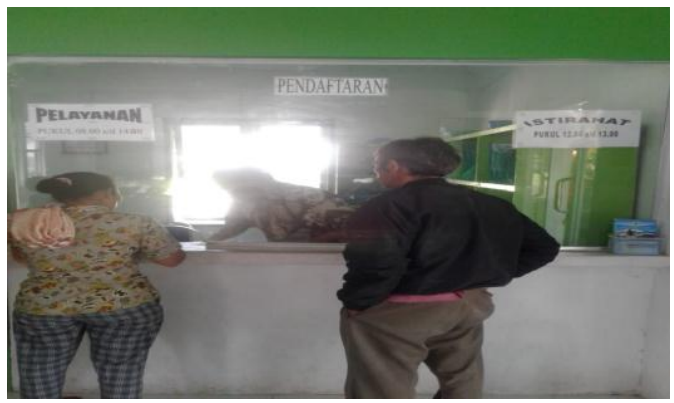

Gambar 2. Ruang Pendaftaran

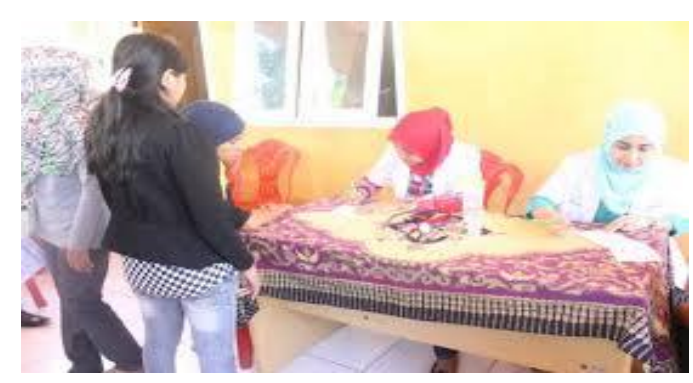

Gambar 3. Proses Pelayanan Pendaftaran

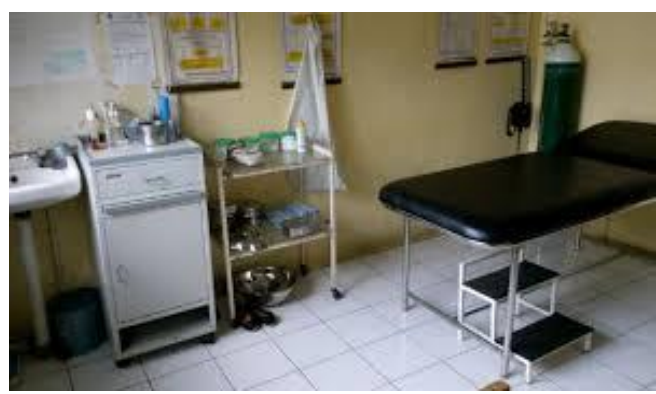

Gambar 4. Ruang IGD Puskesmas

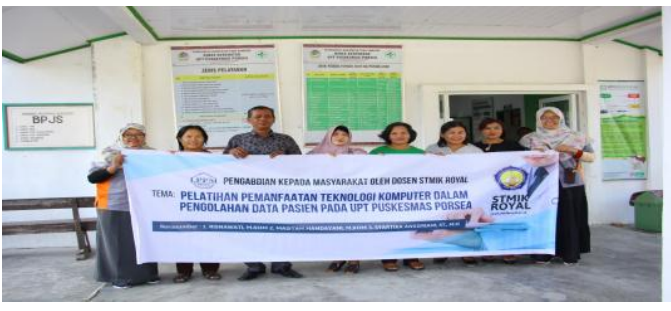

Gambar 5. Foto Bersama dengan Kepala Puskesmas

\section{PEMBAHASAN}

Pada pembahasan ini pelaksanaan kegiatan pengabdian ini berjalan sesuai dengan rencana yang telah ditetapkan. Hal ini disebabkan oleh adanya kerjasama yang baik antara tim pelaksana pengabdian dengan tenaga medis yang terlibat. Pada saat pelaksanaan, tenaga medis yang mengikuti kegiatan pelatihan tersebut dengan semangat dan antusiasme yang tinggi. Hal ini terbukti dengan adanya perhatian dan ketekunan para peserta dalam menjalankan semua instruksi yang diberikan oleh tim pelaksana. Pada waktu pelatihan berlangsung, peserta juga terlihat aktif dalam menanyakan segala hal yang belum mereka ketahui.

Para narasumber mendampingi peserta dengan penuh tanggungjawab dan kesabaran untuk memastikan bahwa seluruh peserta pelatihan dapat menguasai materi dengan baik. Narasumber juga memanfaatkan peserta yang sudah memiliki pengetahuan lebih banyak dari peserta lainnya untuk dapat memberikan bimbingan. Hal tersebut dapat membuat suasana pelatihan menjadi lebih akrab diantara narasumber dan guru-guru. Oleh sebab itu, suasana ini memberikan capaian yang lebih positif demi tercapainya tujuan pelatihan.

Adapun hasil yang dicapai dalam pelatihan ini adalah peserta pelatihan yang merupakan tenaga medis dapat mengolah data pesien lebih efektif dan efisien karena tidak perlu lagi menghitung nilai satu persatu. Selain itu, pelatihan ini memberikan manfaat kepada tenaga medis 
Available online at https://jurnal.stmikroyal.ac.id/index.php/jurdimas

bagaimana memanfaatkan teknologi khususnya komputer dengan lebih bijak lagi.

Materi dalam pelatihan ini dibuat sesuai dengan kebutuhan dalam mengolah data pasien dengan cepat. Bagi tenaga medis yang sudah memiliki keterampilan dalam menggunakan komputer dan menggunakan Ms. Excell dalam proses perhitungan maka mereka akan lebih mudah menguasai rumus-rumus yang diajarkan oleh narasumber. Tetapi sebaliknya, bagi yang masih belum terbiasa menggunakan rumus-rumus perhitungan yang diberikan, maka mereka lebih lambat dalam proses pengolahan data tersebut karena sebelum memasukkan rumus yang diinginkan maka mereka terlebih dahulu harus mengetikkan rumus untuk mengolah data tersebut. Bagi yang belum terbiasa, otomatis hal ini dapat memperlama proses pengolahan data.

Akan tetapi, berdasarkan pemantauan yang dilakukan oleh tim pelaksana selama proses pelatihan, kemajuan yang dicapai oleh tenaga medis yang mengikuti pelatihan memiliki kemajuan yang baik, diantaranya dari yang menggunakan komputer untuk menonton video saja, sekarang tenaga medis dapat menggunakan aplikasi komputer dalam proses pengolahan data pasien mereka dengan lebih mudah dan cepat.

Adapun contoh perhitungan data kunjungan berobat pasien dalam pelatihan dapat dilihat pada gambar di bawah ini:

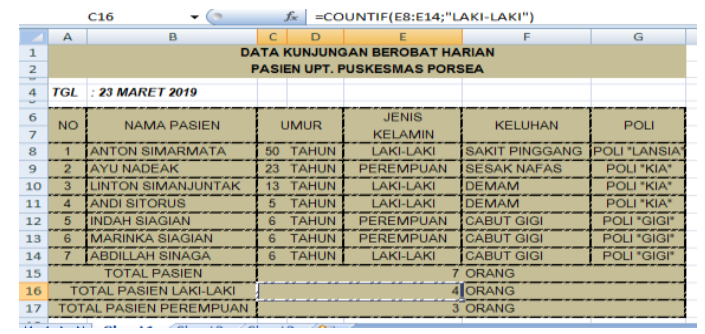

Gambar 6. Tampilan Pemrosesan Data Pasien Menggunakan Rumus
Gambar di atas menunjukkan
adanya fungsi COUNTIF untuk menghitung jumlah pasien laki-laki dan perempuan yang berobat pada hari yang sama.

\section{SIMPULAN}

Berdasarkan kegiatan pengabdian yang telah dilakukan maka dapat disimpulkan bahwa:

1. Kegiatan Pengabdian Masyarakat ini mengambil judul Pemanfaatan Teknologi Komputer Dalam Pengolahan Data Pasien Pada UPT. Puskesmas Porsea dilaksanakan selama 2 hari yaitu pada tanggal 22 Maret -23 Maret 2019

2. Peserta Kegiatan adalah tenaga medis yang terlibat dalam proses pendaftaran pasien.

3. Pelatihan ini sangat bermanfaat bagi tenaga medis karena setelah dilaksanakan pelatihan selanjutnya mereka dapat menerapkan pengolahan data pasien secara komputerisasi sehingg waktu yang digunakan menjadi lebih cepat dan tepat.

4. Hasil dari kegiatan PkM ini adalah pelatihan berjalan dengan baik, lancar dan mendapat respon yang sangat positif dari peserta, hal ini terlihat dari banyaknya pertanyaan-pertanyaan yang diajukan peserta kepada narasumber.

\section{DAFTAR PUSTAKA}

Christoper Lee.2010. Buku Pintar Ms. Excel untuk Pemula.Jakarta. Mediakita

Ir. Pandapotan Sianipar.2008.Cara Mudah Menggunakan Microsoft Excel 2010.Jakarta;Elex Media Komputindo 